\title{
Effects of xylanase supplementation to wheat-based diets on growth performance, nutrient digestibility and gut microbes in weanling pigs
}

\author{
Bing Dong ${ }^{1,2}$, Shaoshuai Liu ${ }^{1,2}$, Chunlin Wang ${ }^{1,2}$, and Yunhe Cao ${ }^{1,2, *}$
}

\author{
* Corresponding Author: Yunhe Cao \\ Tel: +86-10-62733588, Fax: +86-10-62733688, \\ E-mail: caoyh@cau.edu.cn \\ 'State Key Laboratory of Animal Nutrition, China \\ Agricultural University, Beijing 100193, China \\ ${ }^{2}$ Beijing Key Laboratory of Biofeed Additives, China \\ Agricultural University, Beijing 100193, China \\ ORCID \\ Yunhe Cao \\ https://orcid.org/0000-0003-3940-0928
}

Submitted Nov 30, 2017; Revised Jan 5, 2018; Accepted Feb 17, 2018
Objective: This study was designed to investigate the effects of an Aspergillus sulphureus xylanase expressed in Pichia pastoris on the growth performance, nutrient digestibility and gut microbes in weanling pigs.

Methods: A total of 180 weanling pigs (initial body weights were $8.47 \pm 1.40 \mathrm{~kg}$ ) were assigned randomly to 5 dietary treatments. Each treatment had 6 replicates with 6 pigs per replicate. The experimental diets were wheat based with supplementation of $0,500,1,000,2,000$, and 4,000 U xylanase $/ \mathrm{kg}$. The experiment lasted 28 days (early phase, $\mathrm{d} 0$ to 14; late phase, $\mathrm{d} 15$ to 28$)$.

Results: In the early phase, compared to the control, average daily gain (ADG) was higher for pigs fed diets supplemented with xylanase and there was a quadratic response in ADG $(\mathrm{p}<0.05)$. In the entire phase, ADG was higher for the pigs fed 1,000 or $2,000 \mathrm{U} / \mathrm{kg}$ xylanase compared to the control $(\mathrm{p}<0.05)$. The gain to feed ratio was higher for pigs fed diets supplemented with 1,000 or $2,000 \mathrm{U} / \mathrm{kg}$ xylanase compared to the control $(\mathrm{p}<0.05)$. Increasing the amount of xylanase improved the apparent total tract digestibility of dry matter, crude protein, neutral detergent fiber, calcium, and phosphorus during both periods $(\mathrm{p}<0.05)$. Xylanase supplementation $(2,000 \mathrm{U} / \mathrm{kg}$ ) decreased the proportion of Lachnospiraceae (by 50\%) in Firmicutes, but increased Prevotellaceae (by 175\%) in Bacteroidetes and almost diminished Enterobacteriaceae (Escherichia-Shigella) in Proteobacteria.

Conclusion: Xylanase supplementation increased growth performance and nutrient digestibility up to $2,000 \mathrm{U} / \mathrm{kg}$. Supplementation of xylanase $(2,000 \mathrm{U} / \mathrm{kg})$ decreased the richness of gut bacteria but diminished the growth of harmful pathogenic bacteria, such as EscherichiaShigella, in the colon.

Keywords: 16s rRNA Sequencing; Bacterial Community Weanling Pigs; Xylanase

\section{INTRODUCTION}

Wheat has long been used as a major feedstuff for monogastric animals. In 2012, the amount of wheat and its by-products used in feed was 59.8 million tons (China Feed Industry Annual 2012-2013) in China. However, wheat contains non-starch polysaccharides, including xylan, glucan, cellulose, and mannan, that reduce feed efficiency and nutrient digestibility. Of these, xylan makes up dominant proportions averaging 5.4\% to 8.0\% in Australian wheat [1], 5.5\% to $6.5 \%$ in North American wheat [2] and $6.6 \%$ to $8.2 \%$ in Chinese wheat [3]. Xylan, the most abundant polysaccharide in plant cell walls in nature, is therefore considered to be primarily responsible for the anti-nutritional effects of wheat. Mammals cannot digest xylan because they lack endogenous xylanase. Xylanase (EC 3.2.1.8) can degrade xylan by randomly hydrolyzing the $\beta$-1,4-glycosidic bonds producing different length of xylo-oligosaccharides. Thus supplementation of xylanase in feed has been widely applied for chicks and 
pigs to promote growth performance [4]. It is believed that xylanase, as other non-starch polysaccharide (NSP) degrading enzymes, has several actions: partial hydrolysis of nonstarch polysaccharides, decreasing the viscosity of digesta and rupturing plant cell walls to release cellular nutrients for digestion [5,6]. Moreover, the supplementation of xylanase in wheat based diets may produce more short chain oligosaccharides and these products will act as the substrates for gastrointestinal ecology [7]. In this study, we evaluated the effect of an acidic xylanase, cloned from Aspergillus sulphureus and constitutively expressed in Pichia pastoris in our laboratory, in weanling pig diets. Its beneficial effects on hind gut bacterial community was also investigated.

\section{MATERIALS AND METHODS}

\section{Preparation of xylanase}

A xylanase was prepared by fermentation in our lab as previously described [8]. The actual xylanase product used in this study was obtained by mixing $66 \%$ of the liquid fermentation broth produced above with $34 \%$ soybean meal and then air dried for $24 \mathrm{~h}$. This resulted in a xylanase preparation containing approximately 400,000 units (U) of xylanase per kg. One unit of xylanase is defined as the amount of enzyme which liberates $1 \mu \mathrm{mol}$ of total reducing sugar (xylose) per min at the optimal enzymatic reaction conditions of $\mathrm{pH} 2.4$ and $50^{\circ} \mathrm{C}$. The enzyme preparation was tested for contaminating levels of other enzymes using the method of dinitroalicylic acid [9]. Briefly, $5 \mathrm{~g}$ of enzyme powder was dissolved in $50 \mathrm{~mL}$ $\mathrm{Na}_{2} \mathrm{HPO}_{4}$-citric acid buffer ( $\mathrm{pH}$ 2.0) and incubated at room temperature for $30 \mathrm{~min}$. At the same time, the substrate solution was prepared by dissolving $0.16 \mathrm{~g}$ of pure mannan, xylan, $\alpha$-galactose and $\beta$-glucan (Sigma, St Louis, MO, USA) in 20 $\mathrm{mL}$ of $\mathrm{Na}_{2} \mathrm{HPO}_{4}$-citric acid buffer ( $\mathrm{pH}$ 2.4). Equal amounts $(400 \mu \mathrm{L})$ of the enzyme and substrate solutions were mixed and incubated at $65^{\circ} \mathrm{C}$ for $20 \mathrm{~min}$ before stopping the reaction with $1 \mathrm{~mL}$ of 3,5-dinitrosalicylic acid solution. The optical density of the solution was assayed on a spectrophotometer (Beijing PuxiGeneral TU-1901, Beijing, China) at $540 \mathrm{~nm}$. No mannanase, $\beta$-glucanase or $\alpha$-galactosidase activity was detected in the enzyme preparation.

\section{Animal and facilities}

All animal procedures and animal care were approved by the Institutional Animal Care and Use Committee of China Agricultural University (Beijing, China). The experiments were conducted in the Pig Research Facility at the Swine Nutrition Research Centre of National Feed Engineering Technology Research Centre (Chengde, Hebei, China). One nursery barn was used in the study. The barn was a closed facility with mechanical ventilation equipment. The barn was equipped with 36 pens, each pen contained 6 pigs (three barrows and three gilts), resulting in $0.45 \mathrm{~m}^{2}$ per pig $([1.8 \mathrm{~m} \times 1.5 \mathrm{~m}] / 6)$. The floor was one-half slatted concrete. Each pen was equipped with 1 nipple waterer and 1 feeder. A total of 180 crossbred pigs (Duroc $\times$ Landrace $\times$ Yorkshire) with an average initial body weight (BW) of $8.47 \pm 1.40 \mathrm{~kg}$ (average weaning age was $28 \mathrm{~d}$ ) were blocked according to gender, ancestry and BW. Pigs were allotted to one of five dietary treatments $(0,500,1,000,2,000$, and $4,000 \mathrm{U} / \mathrm{kg}$ xylanase in wheat based diets) with six replicates (pen) in each treatment. The diets were formulated to contain $3,400 \mathrm{kcal} / \mathrm{kg}$ of digestible energy, 3,265 kcal/kg of metabolisable energy (ME), $18.76 \%$ of crude protein (CP) and $1.14 \%$ of total lysine (Table 1) and in meal form. As an indigestible marker, $0.3 \%$ chromic oxide $\left(\mathrm{Cr}_{2} \mathrm{O}_{3}\right)$ was added to each diet to calculate apparent total tract digestibility (ATTD) (Table 1). We formulated the diets in a reduced nutrient level (ME: 4\% lower than Nutrient Research Council [10] and 5\% lower of standard ileum digestibility [SID] lysine). The aim was to monitor the significant effects of supplemented xylanase on improvement of the diet digestibility assuming xylanase released more oligosaccharides from wheat based diets. The experiment lasted 28 days divided into 2 stages (early phase, d 0 to 14 ; late phase, d 15 to 28). Pigs had ad libitum access to feed and water. On d 28 of the experiment, one pig from each pen (total three barrows and three gilts for each treatment) was selected to be slaughtered. Colon digesta were collected aseptically and immediately immersed in liquid nitrogen and stored at $-80^{\circ} \mathrm{C}$ for analysis of bacterial community.

Each piglet was weighed on $\mathrm{d} 0,14$, and 28 of the experiment. Feed consumption was recorded daily by weighing out any residual feed from the previous day prior to adding new feed, which was average daily feed intake (ADFI). Average daily gain (ADG) was calculated by dividing total weight gain of pigs with days of experiment. Gain to feed ratio (G:F) was calculated by dividing ADG with ADFI.

Feed samples for each treatment were collected from every batch of feed produced, pooled and mixed within treatment. Fresh fecal samples were taken from each pen on $\mathrm{d} 13$ and 14 of the experiment (phase 1) as well as on $\mathrm{d} 27$ and 28 of the experiment (phase 2) and frozen for later analysis. Fecal samples were collected at least six times a day from the floor of each pen. The fecal samples were pooled within pen and dried in a forced-air drying oven at $65^{\circ} \mathrm{C}$ for $72 \mathrm{~h}$, ground through a 1-mm screen and thoroughly mixed.

The digestibility of various chemical constituents was determined using the reported method [11]. The equation used was as follows:

$$
\mathrm{ND}(\%)=1-[(\mathrm{DC} \times \mathrm{FN}) /(\mathrm{FC} \times \mathrm{DN})] \times 100 \%
$$

Where, ND is the ATTD, DC stands for the content of $\mathrm{Cr}_{2} \mathrm{O}_{3}$ in the experimental diets (\%), $\mathrm{FN}$ represents the content of a chemical constituent in the feces (\%), FC is the content of $\mathrm{Cr}_{2} \mathrm{O}_{3}$ 
Table 1. Ingredient composition and chemical analysis of diets fed to investigate the effects of graded levels of xylanase in weanling pigs

\begin{tabular}{|c|c|c|c|c|c|}
\hline \multirow{2}{*}{ Item } & \multicolumn{5}{|c|}{ Xylanase (U/kg) } \\
\hline & 0 & 500 & 1,000 & 2,000 & 4,000 \\
\hline \multicolumn{6}{|l|}{ Ingredient ( $\%$ as fed) } \\
\hline Corn & 10.45 & 10.45 & 10.45 & 10.45 & 10.45 \\
\hline Extruded soybean & 16.10 & 15.97 & 15.85 & 15.60 & 15.10 \\
\hline Wheat bran & 10.00 & 10.00 & 10.00 & 10.00 & 10.00 \\
\hline Fish meal & 4.40 & 4.40 & 4.40 & 4.40 & 4.40 \\
\hline Whey powder & 5.00 & 5.00 & 5.00 & 5.00 & 5.00 \\
\hline Dicalcium phosphate & 0.80 & 0.80 & 0.80 & 0.80 & 0.80 \\
\hline Limestone & 1.00 & 1.00 & 1.00 & 1.00 & 1.00 \\
\hline Salt & 0.30 & 0.30 & 0.30 & 0.30 & 0.30 \\
\hline Chromic oxide & 0.30 & 0.30 & 0.30 & 0.30 & 0.30 \\
\hline Vitamin-mineral premix ${ }^{1)}$ & 0.50 & 0.50 & 0.50 & 0.50 & 0.50 \\
\hline Xylanase preparation ${ }^{2)}$ & 0.00 & 0.13 & 0.25 & 0.50 & 1.00 \\
\hline Total & 100.00 & 100.00 & 100.00 & 100.00 & 100.00 \\
\hline \multicolumn{6}{|l|}{ Chemical composition (as fed) } \\
\hline Digestible energy $(\mathrm{kcal} / \mathrm{kg})^{3)}$ & 3,400 & 3,400 & 3,400 & 3,400 & 3,400 \\
\hline Metabolisable energy $(\mathrm{kcal} / \mathrm{kg})^{3)}$ & 3,265 & 3,265 & 3,265 & 3,265 & 3,265 \\
\hline Crude protein $(\%)^{4)}$ & 18.76 & 18.71 & 18.68 & 18.78 & 18.90 \\
\hline Lysine $(\%)^{4)}$ & 1.14 & 1.10 & 1.13 & 1.09 & 1.12 \\
\hline Methionine $(\%)^{4)}$ & 0.36 & 0.38 & 0.35 & 0.33 & 0.30 \\
\hline Calcium $(\%)^{4)}$ & 0.67 & 0.64 & 0.65 & 0.63 & 0.69 \\
\hline
\end{tabular}

in the feces (\%), DN is the content of a chemical constituent in the diet (\%).

\section{Chemical analyses}

Feed and fecal samples were analyzed according to the methods of the Association of Official Analytical Chemists (AOAC [12]). Analyses were conducted for moisture (AOAC method 930.15), CP (AOAC method 984.13), calcium (AOAC method 968.08) and phosphorus (AOAC method 965.17). Neutral detergent fiber (NDF) and acid detergent fiber (ADF) were determined using fiber bags and fiber analyzer equipment (Fiber Analyzer, Ankom Technology, Macedon, NY, USA) [13]. Gross energy was measured via an adiabatic oxygen bomb calorimeter (Parr Instruments, Moline, IL, USA). The chromium concentrations of diets and fecal samples were determined after nitric acid-perchloric acid wet ash sample preparation using a Polarized Zeeman Atomic Absorption
Spectrometer (Hitachi Z2000, Tokyo, Japan). All analyses were performed in duplicate and repeated when the results differed by more than $5 \%$.

\section{Statistical analysis}

Data were analyzed using one-way analysis of variance (ANOVA) in accordance with the general linear model procedures of SAS 9.2 (SAS Institute Inc., Cary, NC, USA) utilizing a randomized complete block design by weight, including the terms for treatments and blocks. Each pen was deemed as one experimental unit for growth performance, while an individual pig was considered as the experimental unit for other indices. Interactive matrix algebra procedure (IML) of SAS was adopted to generate the coefficients of unequally spaced contrasts. Subsequently, the linear and quadratic responses of xylanase level were assessed by the orthogonal polynomial contrast. Significance level was set at $\mathrm{p}<0.05$. 


\section{Microbial diversity analysis}

DNA extraction and PCR amplification: Colon digesta samples of six replicates from control and xylanase treated group were blended in equimolar ratios based on concentration for PCR amplicons. The xylanase treated group of 2,000 U/kg xylanase was selected based on results. DNA samples taken from the digesta were subjected to $16 \mathrm{~S}$ rRNA gene sequence-based analysis to examine the characteristic of bacterial communities. Small fragment libraries whose concentration was more than $30 \mathrm{ng} / \mu \mathrm{L}$ were used for PCR amplification. After thawed on ice, the samples centrifuged and mixed thoroughly, Qubit test was used to test the sample concentration. The V4-V5 region of the bacteria $16 \mathrm{~S}$ ribosomal RNA gene were amplified by PCR $\left(95^{\circ} \mathrm{C}\right.$ for $2 \mathrm{~min}$, followed by 25 cycles at $95^{\circ} \mathrm{C}$ for $30 \mathrm{~s}$, $55^{\circ} \mathrm{C}$ for $30 \mathrm{~s}$, and $72^{\circ} \mathrm{C}$ for $30 \mathrm{~s}$ and a final extension at $72^{\circ} \mathrm{C}$ for $5 \mathrm{~min}$ ) using primers 338F $5^{\prime}$-barcode-ACTCCTACGG GAGGCAGCAG-3' and 806R 5'- GGACTACHVGGGTWT CTAAT-3', where barcode is an eight-base sequence unique to each sample.

Illumina MiSeq sequencing: Amplicons were extracted from 2\% agarose gels and purified using the AxyPrep DNA Gel Extraction Kit (Axygen Biosciences, Union City, CA, USA) according to the manufacturer's instructions and quantified using QuantiFluor-ST (Promega, Madison, WI, USA). Purified amplicons were pooled in equimolar and paired-end sequenced $(2 \times 250)$ on an Illumina MiSeq platform according to the standard protocols. The raw reads were deposited into the NCBI Sequence Read Archive (SRA) database (Accession Number: SRP124788).

Processing of sequencing data: Raw fastq files were demultiplexed, quality-filtered using QIIME (version 1.17) with the following criteria: i) The $300 \mathrm{bp}$ reads were truncated at any site receiving an average quality score $<20$ over a $50 \mathrm{bp}$ sliding window, discarding the truncated reads that were shorter than $50 \mathrm{bp}$. ii) exact barcode matching, 2 nucleotide mismatch in primer matching, and reads containing ambiguous characters were removed. iii) only sequences that overlap longer than $10 \mathrm{bp}$ were assembled according to their overlap sequence. Reads which could not be assembled were discarded. Operational taxonomic units (OTUs) were clustered with $97 \%$ similarity cutoff using UPARSE (version $7.1 \mathrm{http} / / /$ drive5. com/uparse/) and chimeric sequences were identified and removed using UCHIME. The taxonomy of each $16 \mathrm{~S}$ rRNA gene sequence was analyzed by RDP Classifier (http://rdp. cme.msu.edu/) against the silva (SSU115)16S rRNA database using confidence threshold of 70\% [14].

\section{RESULTS}

\section{Xylanase Supplementation improved growth performance, and ATTD}

The growth performance of the weanling pigs is presented in Table 2 . In the early phase (d 0 to 14 of the experiment), compared to pigs fed the control diet, ADG were higher for pigs fed diets supplemented groups, and there was a quadratic response in $A D G(p<0.05)$. G:F of supplemented groups showed a quadratic response compared to the control in the early phase $(\mathrm{p}<0.05)$. In the entire phase ( 0 to $\mathrm{d} 28$ of the experiment), ADG was higher for the pigs fed 1,000 or $2,000 \mathrm{U} / \mathrm{kg}$ xylanase compared to pigs fed the control diet $(\mathrm{p}<0.05)$. The $\mathrm{G}: \mathrm{F}$ was higher for pigs fed diets supplemented with 1,000 to $2,000 \mathrm{U} / \mathrm{kg}$ xylanase compared to the control $(\mathrm{p}<0.05)$. Increasing the amount of xylanase in the diet improved $(p<0.05)$ the ATTD of dry matter (DM), CP, NDF, ADF, calcium, and phosphorus during both periods (Table 3 ).

Table 2. Growth performance of weanling pigs fed diets containing graded levels of xylanase ${ }^{1)}$

\begin{tabular}{|c|c|c|c|c|c|c|c|c|}
\hline \multirow{2}{*}{ Item } & \multicolumn{5}{|c|}{ Xylanase (U/kg) } & \multirow{2}{*}{ SEM } & \multicolumn{2}{|c|}{ p-value } \\
\hline & 0 & 500 & 1,000 & 2,000 & 4,000 & & Linear & Quadratic \\
\hline \multicolumn{9}{|c|}{ Early phase, d 0 to 14} \\
\hline ADG $(g)$ & $205^{a}$ & $239^{b}$ & $253^{b}$ & $251^{b}$ & $247^{b}$ & 12 & 0.231 & 0.009 \\
\hline ADFI $(g)$ & 405 & 414 & 423 & 410 & 440 & 24 & 0.955 & 0.742 \\
\hline $\mathrm{G}: \mathrm{F}$ & 0.51 & 0.58 & 0.60 & 0.61 & 0.56 & 0.07 & 0.366 & 0.030 \\
\hline \multicolumn{9}{|c|}{ Late phase, d 15 to 28} \\
\hline ADG $(\mathrm{g})$ & 418 & 457 & 472 & 476 & 448 & 12 & 0.312 & 0.253 \\
\hline ADFI $(g)$ & 690 & 687 & 702 & 681 & 654 & 33 & 0.265 & 0.169 \\
\hline$G: F$ & 0.61 & 0.67 & 0.67 & 0.70 & 0.68 & 0.03 & 0.375 & 0.051 \\
\hline \multicolumn{9}{|c|}{ Entire experiment, d 0 to 28} \\
\hline ADG $(g)$ & $346^{a}$ & $360^{a b}$ & $387^{b}$ & $402^{b}$ & $365^{a b}$ & 10 & 0.138 & 0.021 \\
\hline ADFI (g) & 588 & 598 & 630 & 640 & 617 & 26 & 0.124 & 0.169 \\
\hline $\mathrm{G}: \mathrm{F}$ & 0.59 & 0.60 & 0.61 & 0.63 & 0.59 & 0.02 & 0.241 & 0.048 \\
\hline
\end{tabular}

SEM, standard error of the mean; $A D G$, average daily gain; $A D F I$, average daily feed intake; G:F, gain to feed ratio.

${ }^{1)}$ Value represent the means of six pens with six pigs per pen.

ab Different superscripts represent differ significantly $(p<0.05)$. 
Table 3. Effect of graded levels of xylanase supplementation on apparent total tract digestibility ${ }^{1 \prime}$

\begin{tabular}{|c|c|c|c|c|c|c|c|c|c|}
\hline \multirow{2}{*}{ Digestibility (\%) } & \multicolumn{5}{|c|}{ Xylanase (U/kg) } & \multirow{2}{*}{ SEM } & \multicolumn{3}{|c|}{$p$-value } \\
\hline & 0 & 500 & 1,000 & 2,000 & 4,000 & & ANOVA & Linear & Quadratic \\
\hline \multicolumn{10}{|l|}{ Day 13 and 14} \\
\hline Dry matter & 77.22 & 77.23 & 80.09 & 80.97 & 78.03 & 0.69 & $<0.01$ & $<0.01$ & $<0.01$ \\
\hline Gross energy & 77.93 & 76.07 & 79.73 & 81.12 & 78.56 & 0.70 & $<0.01$ & 0.01 & 0.08 \\
\hline Crude protein & 66.38 & 66.73 & 71.58 & 72.30 & 70.25 & 0.96 & $<0.01$ & $<0.01$ & $<0.01$ \\
\hline Neutral detergent fiber & 49.91 & 54.61 & 55.38 & 59.75 & 54.28 & 2.14 & 0.03 & 0.06 & 0.03 \\
\hline Acid detergent fiber & 46.31 & 50.92 & 51.44 & 57.03 & 51.04 & 2.24 & 0.03 & 0.07 & 0.03 \\
\hline Calcium & 36.38 & 48.25 & 49.59 & 42.64 & 45.81 & 2.12 & $<0.01$ & 0.01 & 0.02 \\
\hline Phosphorus & 33.96 & 38.65 & 46.74 & 46.65 & 44.19 & 3.56 & 0.05 & 0.02 & 0.03 \\
\hline \multicolumn{10}{|l|}{ Day 27 and 28} \\
\hline Dry matter & 79.55 & 80.39 & 82.01 & 82.72 & 81.98 & 0.69 & 0.03 & 0.01 & 0.06 \\
\hline Gross energy & 80.09 & 80.45 & 80.94 & 84.88 & 80.74 & 0.82 & $<0.01$ & 0.10 & 0.05 \\
\hline Crude protein & 71.66 & 72.24 & 74.92 & 76.85 & 74.35 & 1.11 & $<0.01$ & 0.01 & 0.03 \\
\hline Neutral detergent fiber & 48.02 & 58.77 & 57.48 & 59.06 & 57.44 & 1.83 & 0.01 & $<0.01$ & 0.02 \\
\hline Acid detergent fiber & 49.41 & 55.83 & 56.62 & 58.05 & 57.18 & 2.17 & 0.05 & 0.02 & 0.03 \\
\hline Calcium & 37.48 & 46.49 & 44.88 & 47.91 & 45.63 & 1.65 & $<0.01$ & 0.01 & 0.01 \\
\hline Phosphorus & 42.83 & 47.02 & 47.75 & 49.75 & 48.62 & 1.61 & 0.05 & 0.02 & 0.01 \\
\hline
\end{tabular}

SEM, standard error of the mean; ANOVA, analysis of variance.

${ }^{1)}$ Value represent the means of six pens with six pigs per pen.

Diversity of bacterial community in pig colonic digesta To further investigate the mechanism of dietary xylanase on improved growth performance, the colon digesta bacterial richness and diversity in the group of 2,000 U/kg xylanase were determined. After size filtering, quality control and chimera removal, a total of 41,408 and 44,581 valid sequences in colonic digesta of unsupplemented (Control) and supplemented pigs (Xylanase) were obtained, respectively. The OTU numbers of bacterial community were classified from valid sequence with $97 \%$ similarity. The indices of sobs (OTUs), Ace and Chao represent the richness of bacterial community, while Shannon, Simpson, and Coverage values represent the diversity (Table 4). Venn analysis (data not shown) showed that the colonic digesta of control and xylanase treatment shared 250 OTUs, which accounted for $77.88 \%$ of the total OTUs of the control group and $88.65 \%$ of the xylanase group. Firmicutes, Bacteroidetes, and Proteobacteria were dominant phyla in weanling pig colonic digesta, representing over $99 \%$ proportion of total bacterial community compared to the control (Figure 1A). However, the distribution of individual proportions of these three phyla were not equivalent. In Xylanase group (2,000 U/kg), Firmicutes represented $43 \%$ of the total proportion (vs $60 \%$ in control); Bacteroidetes was taken $54 \%$ (vs $21 \%$ in control). Proteobacteria was not detectable in Xylanase group (vs $17 \%$ in control).

When further dissected to bacterial compositions at the family level (Figure 1B), xylanase supplementation decreased the proportion of Lachnospiraceae (by 50\%) in Firmicutes and increased Prevotellaceae (by 175\%) in Bacteroidetes. Xylanase supplementation almost diminished Enterobacteriaceae in Proteobacteria. At the Genus level (Figure 2), we found that the majority of the reduction in Lachnospiraceae was related to the genus Eubacterium_rectale_group (by 55\%). And the diminished Enterobacteriaceae abundance (Figure 3) was related to Escherichia-Shigella genus, a serious pathogenic bacterial strain in gut. The increased Prevotellaceae was related to a series of Prevotella genera (Provotella_9, Prevotellaceae_ NK3B31_group, Prevotella_1 etc), and their variation profile was similar to that of the family of Prevotella.

\section{DISCUSSION}

Weaning is the most challenging event for young piglets as they are forced to encounter nutritional stress changing from

Table 4. Alpha diversity estimators of feces of xylanase supplemented weanling pigs ${ }^{11}$

\begin{tabular}{lccccccc}
\hline Samples/Estimators & Valid sequences & Sobs $^{2)}$ & Ace & Chao & Shannon & Simpson & Coverage \\
\hline Control) $^{3)}$ & 41,408 & 321 & 391.76 & 426.00 & 3.94 & 0.0519 & 0.997 \\
Xylanase $^{3)}$ & 44,581 & 282 & 309.99 & 307.16 & 3.95 & 0.0347 & 0.998 \\
\hline
\end{tabular}

\footnotetext{
1) Pig colonic digesta were collected on $\mathrm{d} 27$ and 28.

2) Sobs are the number of observed operational taxonomic units (OTUs).

${ }^{3)}$ Control was unsupplemented group; Xylanase was the supplemented group with 2,000 U/kg xylanase.
} 

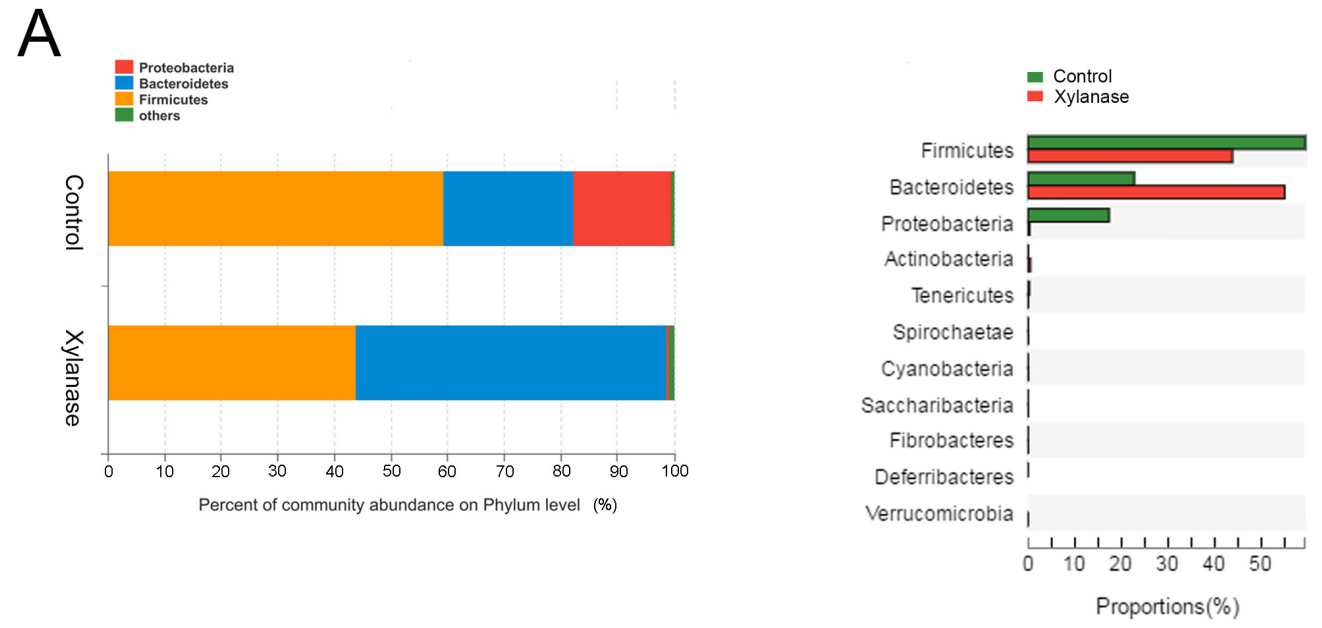

B
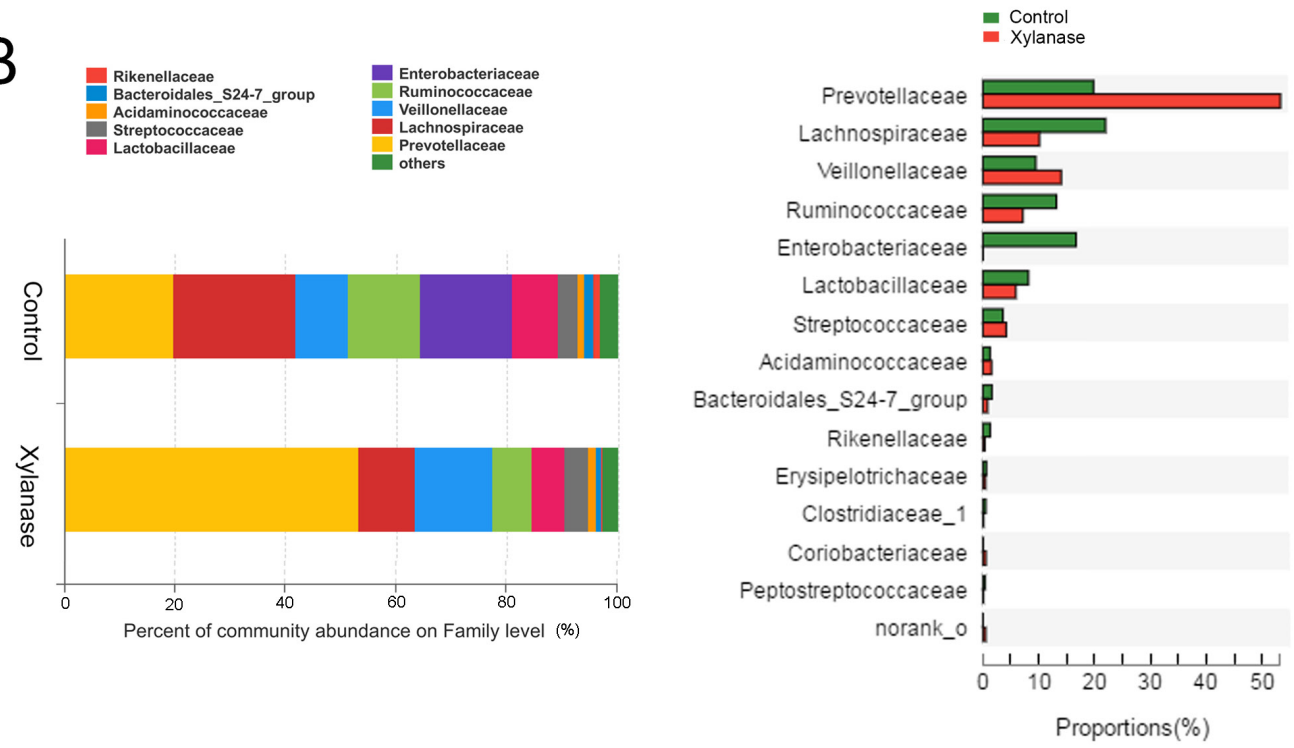

C

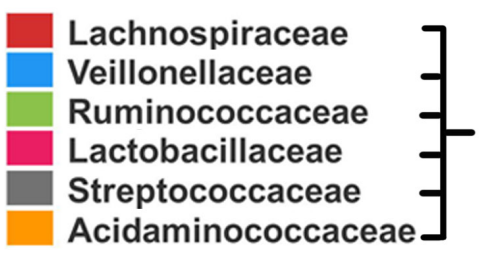

Bacteroidetes $\left[\begin{array}{l}\text { Prevotellaceae } \\ \text { Bacteroidales_S24-7_group } \\ \text { Rikenellaceae }\end{array}\right.$

Firmicutes

Proteobacteria - $\square$ Enterobacteriaceae

Figure 1. Effects of xylanase supplementation on colonic bacterial community of weanling pigs in phylum and family level. Relative read abundance of different bacterial phylum (A) and families (B) within different communities in the colonic digesta in the treatments (Control and Xylanase). Phyla and families with proportion less than 1\% were not listed. Right panels demonstrated the alteration proportion of bacteria. (C) Detailed phylum, family and genus information of representative bacteria was listed. Control was unsupplemented group; Xylanase was the supplemented group with 2,000 U/kg xylanase.

liquid sow milk to a less digestible dry feed, immature immune system, and social stress caused by separation from mothers and commingling with other non-littermate piglets. These disruptions usually cause damage to intestinal epithelia increasing the likelihood for infection by pathogenic microorganisms. Additionally, the immature gastrointestinal tract cannot secret sufficient amount of digestive enzymes for proper digestion and absorption, which worsened the growth of post-weaning pigs. NSP can impact the gastrointestinal tract in two aspects. One is that NSP functions as a substrate to increase the viscosity [15]. This biochemical characteristic is accompanied by some consequent effects such as increased digesta transit times, rate of mucosa cell turnover, mucin secretion and undigested contents. These effects increase microbial size (colony 


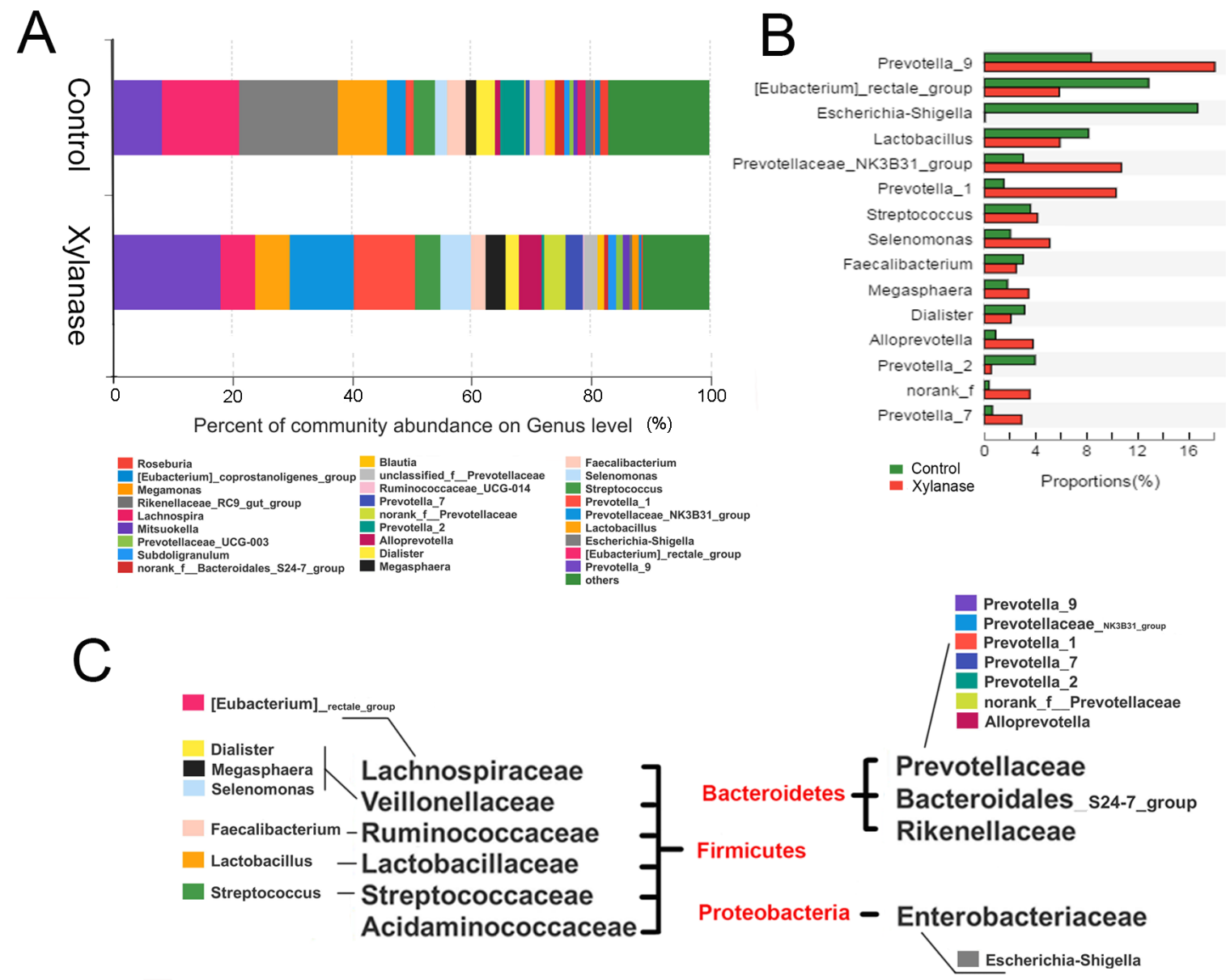

Figure 2. Effects of xylanase supplementation on colonic bacterial community of weanling pigs in genus level. Relative read abundance of different bacterial genus (A) and alteration proportion of the bacteria (B) within different communities in the colonic digesta in the treatments (Control and Xylanase). Genus with proportion less than $1 \%$ were not listed. (C) Detailed phylum, family and genus information of representative bacteria was listed. Control was unsupplemented group; Xylanase was the supplemented group with 2,000 U/kg xylanase.

forming unites) [16] and composition [17]. On the other hand, NSPase, such as xylanase, can reduce digesta viscosity by hydrolysis of NSP and NSP-containing cell walls to decapsulate nutrients for digestion. Xylanase produces numerous shortchain xylo-oligomers [18], which improve small intestinal absorption and limits substrates for large intestinal microbial fermentation.

In this study, we investigated the effect of an acidic $\beta-1,4-$ xylanase, cloned from Aspergillus sulphureus and constitutively expressed in Pichi pastoris, in wheat-based diets on the growth of weanling pigs. NRC recommends nutrient requirements for an optimal growth for pigs. In this study, we formulated the diets with a reduced nutrient level (ME: $4 \%$ lower than NRC and 5\% lower of SID lysine). The aim was to monitor the significant effects of supplemented xylanase on improvement of the diet digestibility assuming xylanase released more oligosaccharides from wheat based diets. If the nutrient level had already met the growth requirement, the additional effect by supplemented xylanase could be saturated. Indeed, we observed that at this nutrient level, ADG and G:F were significantly improved. At this dietary condition, the weanling pigs encountered pathogenic infection which was reflected by colonic Enterobacteriaceae (Escherichia-Shigella). Xylanase supplementation at 2,000 U/mg significantly diminished pathogenic Enterobacteriaceae (Escherichia-Shigella) in the colon. We found increased ADG and G:F in the early phase ( $\mathrm{d} 0$ to $\mathrm{d} 14$ of the experiment) and the entire phase ( $\mathrm{d} 0$ to $\mathrm{d}$ 28 of the experiment). The ATTD of DM, CP, NDF, calcium, and phosphorus were all improved indicating that, besides digested plant cell walls, the supplemented xylanase also systemically improved action of other digestive enzymes on the wheat-based diet. It enhanced an overall absorption of dietary nutrients including crude protein, crude fat, crude fiber, organic matter etc. These results were consistent with similar reports in weanling pigs $[19,20]$. We used soybean meal as the carrier for xylanase preparation, and conducted the substitution of extruded soybean. As the proportion of xylanase preparation increased, the extruded soybean amount decreased. 


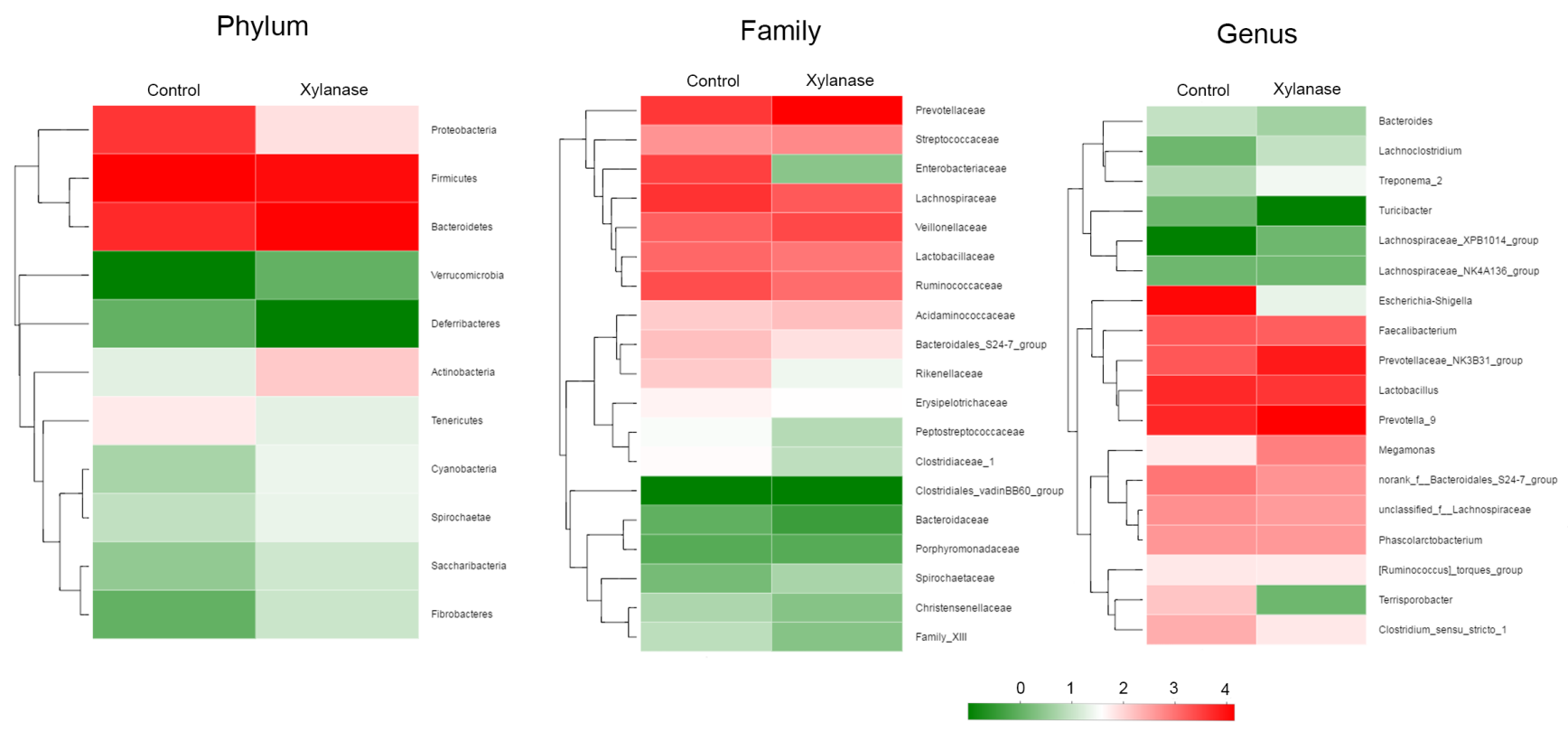

Figure 3. Double hierarchical dendrogram to illustrate effects of xylanase supplementation on bacterial community in colonic digesta of weanling pigs. The distribution of luminal bacteria in the colonic digesta analyzed from phylum, family to genus level, respectively. The bacterial distribution among the samples bacterial phylogenetic tree was calculated by using the neighbor-joining method and the relationship among samples was determined by Bray distance and the complete clustering method. The heatmap plot depicts the relative percentage of each bacterial are depicted by color intensity with the legend indicated at the bottom of the figure. Clusters based on the distance of the eight samples along the X-axis and the bacterial families along the $Y$-axis are indicated in the upper and left of the figure, respectively. Control was unsupplemented group; Xylanase was the supplemented group with 2,000 U/kg xylanase.

Soybean meal contains slightly lower fat than extruded soybean, which might be the reason that at the highest dose of xylanase (4,000 IU), ADG and G:F showed quadratic responses. On the other hand, the created gut microenvironment favored the growth of beneficial bacteria and inhibited harmful bacterial strains. Escherichia_Shigella can cause severe diarrhea in animals. In this study, the pathogenic Escherichia_Shigella were almost diminished by dietary xylanase supplementation. The xylanase supplementation decreased the overall diversity of bacterial community which agrees with a previous report that fermented swine feces in the presence of starch reduced the bacterial diversity [21].

It is interesting that xylanase supplementation $(2,000 \mathrm{U} / \mathrm{kg})$ decreased abundance of the phylum Firmicutes which were mainly contributed by f Eubacterium_rectale_group (21.5\% to $13.1 \%$ in Firmicutes in genus level), an acetate-converting butyrate producer in human colon bacteria [22]. Selenomonas bovi spp (3.4\% to $11.5 \%$ in Firmicutes in genus level) and Megasphaera elsdenii spp (2.9\% to $7.5 \%$ in Firmicutes in genus level) were increased. Selenomonas_bovi spp can produce acetate, propionate and lactate [23] and Megasphaera elsdenii spp are lactate-utilizing bacteria to produce lactic acid [24]. This indicates that xylanase supplementation $(2,000 \mathrm{U} / \mathrm{kg})$ modulated the content of short chain fatty acids in the intestine which may act to counteract complications during post weaning period.

The pylum Bacteroidetes were increased from $22.7 \%$ to
54.5\%, which were mainly represented by Prevotella_9, Pretellaceae_NK3B31_group and Prevotella_1 etc. Prevotella are most abundant in the rumen and hind gut of cattle and sheep to help the breakdown of carbohydrates. The abundance of Prevotella is considered a discriminative taxon in agrarian residence [25]. In this study, the increased proportion of Prevotella increased with xylanase supplementation. It indicates that digestible carbohydrate availability along the length of the intestinal tract allowed enrich the growth of Prevotella.

In conclusion, with modulating the balance of ecophysiology of the total bacterial communities in the intestine including diminished the growth of Escherichia_Shigella and increased Prevotella and series of beneficial bacteria strains, dietary xylanase supplementation enhanced growth and feed utilization of weanling piglets up to $2,000 \mathrm{U} / \mathrm{kg}$.

\section{CONFLICT OF INTEREST}

We certify that there is no conflict of interest with any financial organization regarding the material discussed in the manuscript.

\section{ACKNOWLEDGMENTS}

This work was supported by the Scientific and Technical Supporting Programmes (2013BAD10B01) and Beijing Science and Technology Project (D161100006116001). 


\section{REFERENCES}

1. Choct M, Hughes RJ, Annison G. Apparent metabolisable energy and chemical composition of Australian wheat in relation to environmental factors. Aust J Agric Res 1999;50: 447-52.

2. Wootton M, Acone L, Wills R, et al. Pentosan levels in Australian and north American feed wheats. Aust J Agric Res 1995;46:389-92.

3. Li CX, Qiu CB, Jiang LN, et al. Research on the content of pentosane in wheat grain. J Triticeae Crops 2002;22:47-50.

4. Simon O. The mode of action of NSP hydrolyzing enzymes in the gastrointestinal tract. J Anim Feed Sci 1998;7:115-23.

5. Castanon JIR, Flores MP, Pattersson D. Mode of degradation of non-starch polysaccharides by feed enzyme preparations. Anim Feed Sci Technol 1997;68:361-5.

6. Meng X. Improved nutrient utilization and growth performance of broiler chickens fed diets supplemented with multicarbohydrase enzyme preparations [ $\mathrm{PhD}$ thesis]. Winnipeg, MB, Canada: University of Manitoba. 2005

7. Pluske JR, Pethick DW, Hopwood DE, Hampson DJ. Nutritional influences on some major enteric bacterial diseases of pig. Nutr Res Rev 2002;15:333-71.

8. Cao Y, Qiao J, Li Y, Lu W. De novo synthesis, constitutive expression of Aspergillus sulphureus $\beta$-xylanase gene in Pichia pastoris and partial enzymic characterization. Appl Microbiol Biotechnol 2007;76:579-85.

9. Chen X, Cao Y, Ding Y, et al. Cloning, functional expression and characterization of Aspergillus sulphureus $\beta$-mannanase in Pichia pastoris. J Biotechnol 2007;128:452-61.

10. NRC. Nutrient requirements of swine. Washington, DC, USA: National Academy Press; 2012.

11. Fan MZ, Sauer WC. Determination of true ileal amino acid digestibility and the endogenous amino acid outputs associated with barley samples for growing-finishing pigs by the regression analysis technique. J Anim Sci 2002;80:1593-605.

12. Thiex NJ, Anderson S, Gildemeister B. Crude fat, di-ethyl ether extraction, in feed, cereal grain, and forage (Randall/Soxtec/ submersion method): collaborative study. J AOAC Int 2003; 86:888-98.

13. Van Soest PJ, Robertson JB, Lewis BA. Methods for dietary fiber, neutral detergent fiber, and nonstarch polysaccharides in relation to animal nutrition. J Dairy Sci 1991;74:3583-97.
14. Katherine RA, Carl JY, Angela K, et al. Habitat degradation impacts black howler monkey (Alouatta pigra) gastrointestinal microbiomes. ISME J 2013;7:1344-53.

15. Ellis PR, Roberts FG, Low AG, Morgan LM. The effect of high-molecular-weight guar gum on net apparent glucose absorption and net apparent insulin and gastric inhibitory polypeptide production in the growing pig: relationship to rheological changes in jejunal digesta. Br J Nutr 1995;74:53956.

16. Hübener K, Vahjen W, Simon O. Bacterial responses to different dietary cereal types and xylanase supplementation in the intestine of broiler chicken. Arch Anim Nutr 2002;56:167-87.

17. Choct M, Hughes RJ, Wang J, et al. Increased small intestinal fermentation is partly responsible for the antinutritive activity of non-starch polysaccharides in chickens. Br Poult Sci 1996; 37:609-21.

18. Apajalahti J, Bedford M. Nutrition effects on the microflora of the GI tract. In Proceedings of the 19th Western Nutrition Conference. Saskatoon, SK, Canada: University of Saskachewan; 1998. pp. 60-8.

19. Sterk A, Verdonk JM, Mul AJ, et al. Effect of xylanase supplementation to a cereal-based diet on the apparent faecal digestibility in weanling piglets. Livest Sci 2007;108:269-71.

20. Yin YL, Mcevoy JDG, Schulze H, et al. Apparent digestibility (ileal and overall) of nutrients and endogenous nitrogen losses in growing pigs fed wheat (var. Soissons) or its by-products without or with xylanase supplementation. Livest Prod Sci 2000;62:119-32.

21. Ricca DM, Ziemer CJ, Kerr BJ. Changes in bacterial communities from swine feces during continuous culture with starch. Anaerobe 2010;16:516-21.

22. Louis P, Flint HJ. Diversity, metabolism and microbial ecology of butyrate-producing bacteria from the human large intestine. FEMS Microbiol Lett 2009;294:1-8.

23. Zhang K, Dong X. Selenomonas bovis sp. nov., isolated from yak rumen contents. Int J Syst Evol Microbiol 2009;59:2080-3.

24. Kajihara Y, Yoshikawa S, Cho Y, et al. Preferential isolation of Megasphaera elsdenii from pig feces. Anaerobe 2017;48:1604.

25. Wu GD, Chen J, Hoffmann C, et al. Linking long-term dietary patterns with gut microbial enterotypes. Science 2011;334:1058. 